\title{
Heritable Features of the Optic Disc: A Novel Twin Method for Determining Genetic Significance
}

\author{
Alex W. Hewitt, ${ }^{1,2}$ Johan P. Poulsen, ${ }^{1}$ Wallace L. M. Alward, ${ }^{3}$ Sonya L. Bennett, ${ }^{4}$ \\ Wido M. Budde, ${ }^{5}$ Richard L. Cooper, ${ }^{6}$ Jamie E. Craig, ${ }^{2}$ John H. Fingert, ${ }^{3}$ Paul J. Foster, ${ }^{4}$ \\ David F. Garway-Heath, ${ }^{4}$ Catherine M. Green, ${ }^{7}$ Christopher J. Hammond, ${ }^{8}$ \\ Soban S. Hayreh, ${ }^{3}$ Jost B. Jonas, ${ }^{5}$ Paul L. Kaufman, ${ }^{9}$ Neil R. Miller, ${ }^{10}$ William H. Morgan, ${ }^{11}$ \\ Nancy J. Newman, ${ }^{12}$ Harry A. Quigley, ${ }^{10}$ Jobn R. Samples, ${ }^{13}$ George L. Spaeth,${ }^{14}$ \\ Konrad Pesudovs, ${ }^{2}$ and David A. Mackey ${ }^{1,15}$
}

Purpose. Numerous genetic diseases and environmental stimuli affect optic nerve morphology. The purpose of this study was to identify the principal heritable components of visible optic nerve head structures in a population-based sample of twins.

Methods. Fifteen optic nerve specialists viewed stereoscopic optic nerve head photographs (Stereo Viewer-II; Pentax Corp., Tokyo, Japan) from 50 randomly selected monozygotic or

From the ${ }^{1}$ Centre for Eye Research Australia, University of Melbourne, Royal Victorian Eye and Ear Hospital, Melbourne, Australia; the ${ }^{2}$ National Health and Medical Research Council (NHMRC) Centre for Clinical Eye Research, Department of Ophthalmology, Flinders University, Flinders Medical Centre, Adelaide, Australia; the ${ }^{3}$ Department of Ophthalmology, University of Iowa, Iowa City, Iowa; the ${ }^{4}$ Glaucoma Research Unit, Moorfields Eye Hospital, London, United Kingdom; the ${ }^{5}$ Department of Ophthalmology, Faculty of Clinical Medicine Mannheim, University of Heidelberg, Mannheim, Germany; the ${ }^{6}$ Tasmanian Eye Clinics, Launceston, Australia; the ${ }^{7}$ Glaucoma Research Unit, Royal Victorian Eye and Ear Hospital, Melbourne, Australia; the ${ }^{8}$ Twin Research and Genetic Epidemiology Unit, St. Thomas' Hospital, London, UK; the 'Department of Ophthalmology and Visual Sciences University of Wisconsin (UW) School of Medicine and Public Health UW Clinical Science Center, Madison, Wisconsin; the ${ }^{10}$ Department of Ophthalmology, The Johns Hopkins Medical Institutions, Baltimore, Maryland; the ${ }^{11}$ Lions Eye Institute, University of Western Australia, Nedlands, Australia; the ${ }^{12}$ Department of Ophthalmology, Emory University School of Medicine, Emory Eye Center, Atlanta, Georgia; the ${ }^{13}$ Casey Eye Institute, Portland, Oregon; the ${ }^{14} \mathrm{~W}$ illiam and Anna Goldberg Glaucoma Service and Research Laboratories, Wills Eye Hospital/Jefferson Medical College, Philadelphia, Pennsylvania; and the ${ }^{15}$ Department of Ophthalmology, University of Tasmania, Royal Hobart Hospital, Hobart, Australia.

Supported by NHMRC Project Grant 350415, the Ophthalmic Research Institute of Australia, the American Health Assistance Foundation, and NHMRC Enabling Grant 310667. AWH is supported by an NHMRC Medical Postgraduate Scholarship, and DAM is the recipient of a Pfizer Australia research fellowship.

Submitted for publication December 12, 2006; revised January 17, 2006; accepted March 14, 2007.

Disclosure: A.W. Hewitt, None; J.P. Poulsen, None; W.L.M. Alward, None; S.L. Bennett, None; W.M. Budde, None; R.L. Cooper, None; J.E. Craig, None; J.H. Fingert, None; P.J. Foster, None; D.F. Garway-Heath, None; C.M. Green, None; C.J. Hammond, None; S.S. Hayreh, None; J.B. Jonas, None; P.L. Kaufman, None; N.R. Miller, None; W.H. Morgan, None; N.J. Newman, None; H.A. Quigley, None; J.R. Samples, None; G.L. Spaeth, None; K. Pesudovs, None; D.A. Mackey, None

The publication costs of this article were defrayed in part by page charge payment. This article must therefore be marked "advertisement" in accordance with 18 U.S.C. $\$ 1734$ solely to indicate this fact.

Corresponding author: Alex W. Hewitt, Department of Ophthalmology, Flinders University, Bedford Park, South Australia, Australia, 5042; hewitt.alex@gmail.com. dizygotic twin pairs. Before viewing, each expert was questioned about which optic nerve head traits they believed were inherited. After viewing a standardized teaching set, the experts indicated which twin pairs they thought were monozygotic. Participants were then questioned about how their decisions were reached. A rank-ordered Rasch analysis was used to determine the relative weighting and value applied to specific optic nerve head traits.

RESUlts. The proportion of twin pairs for which zygosity was correctly identified ranged from $74 \%$ to $90 \%$ (median, $82 \%$ ) across the panel. Experts who correctly identified the zygosity in more than $85 \%$ of cases placed most weighting on shape and size of the optic disc and cup, whereas experts with the lowest scores placed greater weighting on the optic nerve head vasculature in reaching their decisions.

Conclusions. In determining the genetic components of the optic nerve head, the results of this study suggest that the shape and size of the optic disc and cup are more heritable and should receive a greater priority for quantification than should vascular features. (Invest Ophthalmol Vis Sci. 2007;48: 2469-2475) DOI:10.1167/iovs.06-1470

$\mathrm{U}$ nderstanding the principal factors that contribute to variation in human traits is important, because genetic or environmental determinants of these traits may also be related to disease susceptibility. Quantitative traits are inherently more powerful for disease loci identification than attempting to map dichotomous (present/absent) diseases such as glaucoma, given their relative rarity in the population. ${ }^{1}$

The optic nerve head (ONH), which is bounded by Elschnig's ring as demarcated by the termination of Bruch's membrane, is composed of numerous quantifiable anatomic structures. ${ }^{2}$ Ganglion cell axons converge at the $\mathrm{ONH}$, to exit the eye in a crude retinotopographic pattern. ${ }^{3}$ Similarly, retinal arteries and veins either enter or leave the eye, respectively, through this scleral foramen. Various diseases with a genetic basis manifest clinically in the form of altered architecture of both the intra- and parapapillary regions of the ONH. ${ }^{4}$ It would be helpful to understand which ONH characteristics should be prioritized for quantitative trait loci (QTL) analysis.

In the prioritization of ONH traits for QTL investigation, it should be remembered that different disease processes may result in the same phenotypic appearance, but also that pleiotropy may occur, in that a single disease may cause a variable $\mathrm{ONH}$ phenotype. For example, in addition to the classic glaucomatous optic cup excavation (which can be focal or diffuse) one may see retinal artery narrowing and expansion of the zone of $\beta$-parapapillary atrophy in primary open-angle glau- 
coma. $^{2,5}$ In addition, other genetic diseases cause other abnormalities of the $\mathrm{ONH}$, such as the presence of telangiectatic vessels in some patients with Leber hereditary optic neuropathy. ${ }^{6}$ Nevertheless, the genes underlying the many diseases that affect the $\mathrm{ONH}$ may be identified through investigating its chief heritable components.

Common variation (or nucleotide polymorphisms) in a gene may influence its expression, which in part explains the normal variance of trait. However, other variants may completely disrupt a gene's function, thereby precipitating a diseased state. The work by Zhu et al. ${ }^{7}$ serves as a case in point for using such a model to identify genes involved in complex diseases. They found that a large proportion (74\%) of the genetic liability for normal variation in eye color is due to a QTL in the OCA2 gene, a gene previously implicated in causing oculocutaneous albinism. ${ }^{8}$ Mutations that completely disrupt the function of both copies of the OCA2 gene result in the disease phenotype of oculocutaneous albinism. ${ }^{8}$ Recently, fine mapping of the OCA2 gene in discordant twins has identified three common polymorphisms in intron 1 that account for this large genetic effect that determines normal eye color in the general population.'

The purpose of this study was to determine which features of the ONH are primarily genetically determined. ONH photographs from randomly selected twin pairs were viewed by practitioners who have a subspecialist interest in the optic nerve. These experts, who were masked to zygosity, attempted to identify which pairs they thought were monozygotic (MZ) and which they thought were dizygotic (DZ). The underlying premise was that the ONH traits that are most highly heritable would be those on which the experts who were the most proficient at correctly identifying twin-pair zygosity based their decisions. In a second experiment, a random series of an additional set of MZ twins were selected, and the right $\mathrm{ONH}$ photograph was displayed, with the expert then randomly viewing either the same person's left $\mathrm{ONH}$, flipped horizontally to appear as a right $\mathrm{ONH}$, or the right $\mathrm{ONH}$ from the $\mathrm{MZ}$ pair. Each expert was asked to nominate which of the latter two most resembled the ONH first viewed. We reasoned that major epigenetic factors would account for variation in $\mathrm{ONH}$ morphology should each expert be able to nominate the $\mathrm{ONH}$ photographs from the same person consistently. Conversely, mirroring or laterality would be important in ONH embryogenesis if the experts were consistently nominating the right $\mathrm{ONH}$ photographs from the MZ pair as being most similar. Overall, the results of this study allow for the prioritization of quantifiable $\mathrm{ONH}$ traits for further genetic investigation.

\section{Materials and Methods}

\section{Subjects Recruitment and Study Protocol}

Twin pairs were identified as part of the Twins Eye Study in Tasmania (TEST) and were recruited from the general population through local media campaigns as well as through a national registry. The Australian twin registry includes more than 30,000 sets of twins. Invitations were then were sent directly to all registered Tasmanian twins $(>1000$ eligible sets). The relevant ethics committees of the University of Tasmania as well as the Royal Victorian Eye and Ear Hospital approved the study, and the protocol adhered to the tenets of the Declaration of Helsinki. Each subject or his or her respective legal guardian provided written informed consent before participation.

All recruited twins underwent a comprehensive clinical examination that included anterior segment examination, intraocular pressure measurement, corneal pachymetry, refraction, and a mydriatic optic disc assessment. Simultaneous stereoscopic optic disc photographs were obtained with a fundus camera (3-Dx/F; Nidek, Gamagori, Japan) on 35-mm slide film (Ektachrome; Eastman Kodak, Melbourne, Australia). For all twin pairs, zygosity was determined by DNA analysis with the following poly- morphic microsatellite markers: D2S2211 (7 alleles); D3S1267 (13 alleles); D6S257 (11 alleles); D8S284 (8 alleles); D11S4151 (6 alleles); D12S345 (10 alleles); D14S283 (9 alleles), and D17S1852 (12 alleles). According to the models developed by Nyholt, our genotyping protocol would falsely classify a DZ pair as MZ in 1 of 4907 cases..$^{10}$

Seventy-seven twin pairs were selected at random from the complete TEST set $(n>400)$. The mean \pm SD age of the selected twins was $30.6 \pm 11.8$ years (range, 7-63 years). Color 35-mm slides of each subject's ONH were viewed (Stereo Viewer-II (Pentax Imaging Company, Golden, CO). All identifying information was removed from each stereoscopic slide before grading.

\section{Experiment Design}

After an initial pilot (viewed by RLC, PLK, CJH, and SSH), 15 optic disc experts (WLA, SLB, WMB, JEC, JHF, PJF, DG-H, CMG, JBJ, NRM, WHM, NJN, HAQ, JRS, GLS), masked to zygosity, viewed the selected slides. Before viewing the slides, these experts were questioned in an unstructured manner about $\mathrm{ONH}$ traits that they believed were inherited. Then, after viewing a standardized teaching set of slides from 5 pairs of $\mathrm{MZ}$ and 5 pairs of $\mathrm{DZ}$ twins, the experts were asked to indicate, in a forced-choice manner, the zygosity of 50 twin pairs. On completion of the full set, experts were questioned qualitatively about how their decisions were reached and then were asked to weight (between 0 and 10) quantitatively the relative importance assigned to specific $\mathrm{ONH}$ traits. These specific ONH traits included CDR, optic disc size, optic cup size, optic cup depth, optic disc shape, and optic cup shape, along with overall neuroretinal rim appearance, retinal vessel diameters, location of the vascular trunk, vascular pattern within the optic disc margin, vascular pattern beyond the optic disc margin, the presence of cilioretinal vessels, and the presence of parapapillary atrophy.

In the second experiment, each expert was shown ONH photographs from 17 sets of $\mathrm{MZ}$ twin pairs. The experts then viewed a right ONH photograph from one of the MZ twin pairs and attempted to determine whether the same individual's left $\mathrm{ONH}$, flipped horizontally a

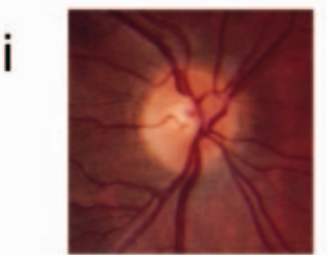

ii

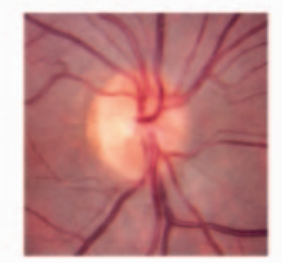

iii

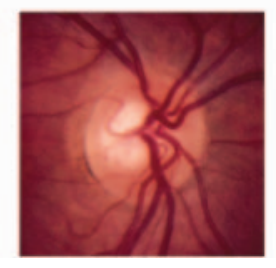

b
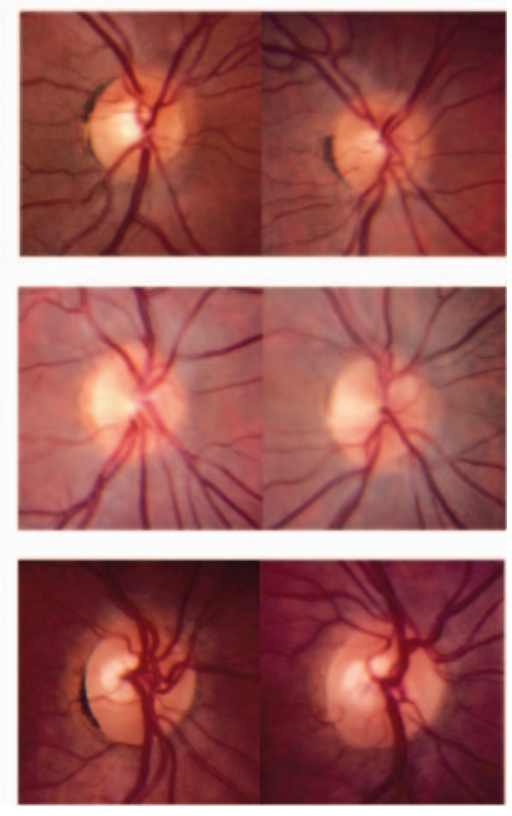

FIGURE 1. ONH photographs of MZ twin pairs for which each expert was asked, after viewing the right ONH from one of the MZ twin pairs (a), whether the same individual's left ONH, flipped horizontally to appear as a right $\mathrm{ONH}$, or the right $\mathrm{ONH}$ from the $\mathrm{MZ}$ twin, most resembled the first. In examples (i) and (iii), ONH photographs (a) and (c) were from the same individual, whereas in (ii), photographs (a) and (b) are from the same individual. 

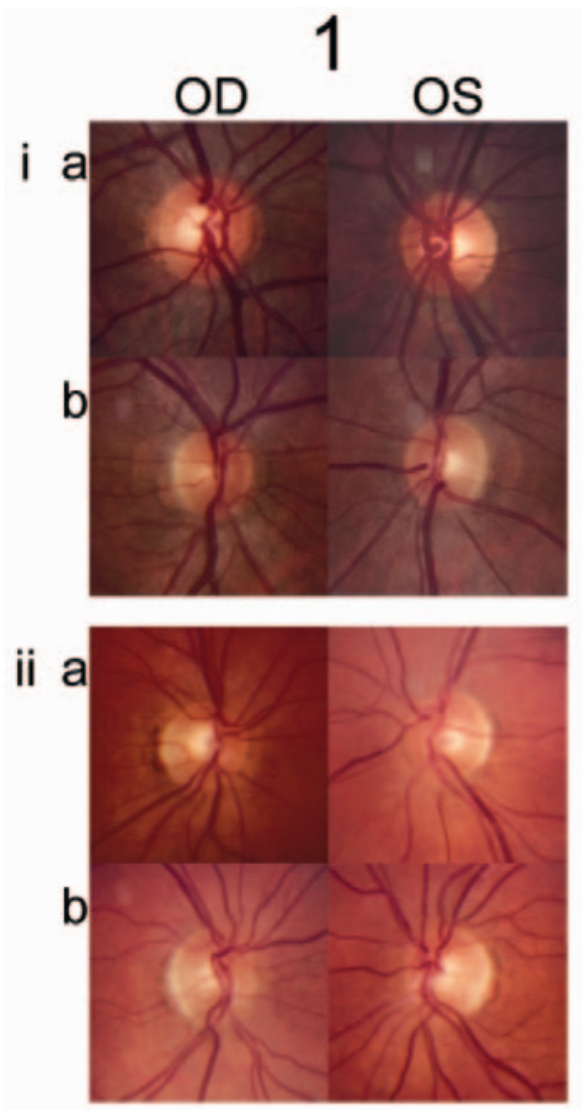

\section{iii}

Figure 2. ONH photographs of twin pairs. Column 1: examples of twin pairs in whom the zygosity was identified correctly by each expert; column 2: examples of twin pairs in whom zygosity was most frequently incorrectly nominated. In both columns, twin pair (i) was DZ, whereas twin pairs (ii) and (iii) were MZ.
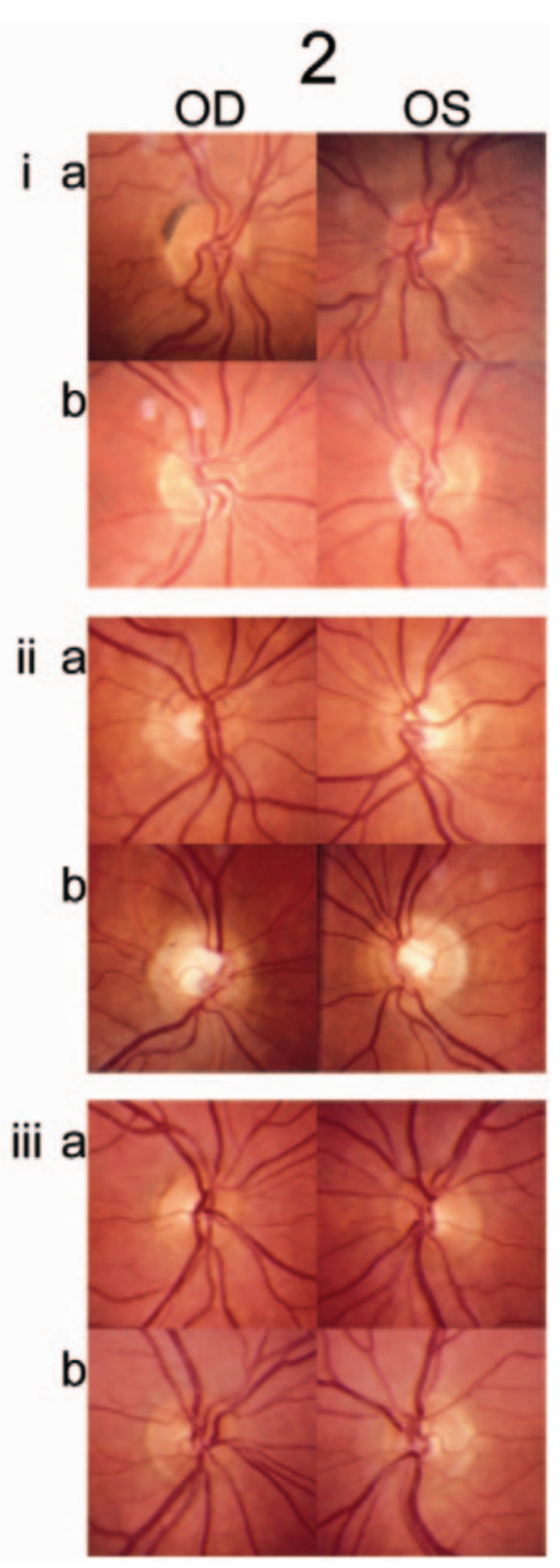

to appear as a right $\mathrm{ONH}$, or the right $\mathrm{ONH}$ from the fellow $\mathrm{MZ}$ twin most resembled the first photograph (Fig. 1).

\section{Data Analysis}

As a measure of reproducibility and to test for fatigue, the proportion of correctly identified twin pairs in the first set of 25 was compared with that in the last set of 25 by the Fischer exact test (SPSS 12.0.1; SPSS Inc, Chicago, IL).

The responses to the postexperiment structured questionnaire were analyzed by using a Rasch approach (WinSteps 3.61.1 program; WinSteps, Chicago, IL). ${ }^{11}$ Rasch analysis allowed the usefulness of specific ONH traits, as weighted by different graders, to be measured on a common logit scale, thereby allowing direct comparison. The Rasch model does not assume values for response categories (e.g., 0, 1, 2. .) rather it assumes that all categories are on the same underlying latent variable. ${ }^{12}$ Categories that were disordered or underutilized were collapsed into adjacent categories. Category probability curves were reviewed to ensure goodness of fit in the probability of observing the relative weighting of each collapsed category at each point on the latent $\mathrm{ONH}$ variable. ${ }^{13} \mathrm{~A}$ rank-ordered analysis was used, whereby each grader's ability was rated by the percentage of twin pairs for whom they had nominated the correct zygosity. ${ }^{14}$ This percentage then was empirically adjusted from proportions to logits to allow sensible fit statistics. The $t$-standardized, mean-square statistics that are used to compare the predicted responses with the observed were reviewed, to monitor the compatibility of the data with the Rasch model. Outliersensitive fit (outfit) mean square is the conventional sum of squared standardized residuals and is sensitive to occasional responses that differ from the expected response, whereas for the informationweighted fit (infit) mean square, each squared standardized residual value is first weighted by its variance and then summed, so as to tolerate extreme responses. ${ }^{13}$ Values predictive of measurement are deemed to fall generally between 0.5 and $1.5 .{ }^{13}$ The first section of the experiment can be performed online at www.twinseyestudy.com.

\section{Results}

The proportions of correctly nominated twin-pair zygosities ranged from $74 \%$ to $90 \%$ (median $82 \%$ ) across the 15 graders. 
TABLE 1. Relative Score and Responses from Each Ophthalmic Expert

\begin{tabular}{|c|c|c|c|c|c|c|}
\hline Expert & $\begin{array}{c}\text { Correct } \\
\text { Zygosity } \\
\text { Nominations } \\
(\%)\end{array}$ & $\begin{array}{l}\text { MZ Twins } \\
\text { Nominated } \\
\quad \text { as DZ } \\
\quad(n)\end{array}$ & $\begin{array}{l}\text { DZ Twins } \\
\text { Nominated } \\
\text { as MZ } \\
\quad(n)\end{array}$ & Pre-experiment Response & Postexperiment Response & $\begin{array}{l}\text { Correct MZ } \\
\text { Matching } \\
\quad(\%)\end{array}$ \\
\hline A & 90 & 3 & 2 & $\begin{array}{l}\text { Size and shape of disc and cup; } \\
\text { tilting of disc; depth of cup; } \\
\text { slope/profile of neuroretinal } \\
\text { rim; vessel pattern; myopic } \\
\text { crescent may be useful }\end{array}$ & $\begin{array}{l}\text { Shape and depth of cup; shape and } \\
\text { tilting of disc; angulation of } \\
\text { vessels through the lamina; vessel } \\
\text { pattern not useful; cilioretinal } \\
\text { vessels not useful }\end{array}$ & 47.1 \\
\hline B & 90 & 3 & 2 & $\begin{array}{l}\text { Size of disc; size and shape of } \\
\text { cup; vessel arrangement; scleral } \\
\text { crescent may be useful; clarity } \\
\text { of neuroretinal rim; } \\
\text { neuroretinal rim shape }\end{array}$ & $\begin{array}{l}\text { Orientation of disc; size of disc; size } \\
\text { of cup; shape and site of } \\
\text { prominence of neuroretinal rim; } \\
\text { vessel pattern not useful }\end{array}$ & 70.6 \\
\hline $\mathrm{C}$ & 86 & 4 & 3 & $\begin{array}{l}\text { Size and shape of disc; vessel } \\
\text { trunk course; depth and shape } \\
\text { of cup; parapapillary atrophy } \\
\text { may be useful }\end{array}$ & $\begin{array}{l}\text { Shape and size of disc; depth, shape } \\
\text { and size of cup; location of } \\
\text { highest region of nerve fiber } \\
\text { layer; parapapillary atrophy }\end{array}$ & 76.5 \\
\hline $\mathrm{D}$ & 86 & 5 & 2 & $\begin{array}{l}\text { Size of disc; tilting and shape of } \\
\text { disc; depth of cup/nerve head; } \\
\text { CDR; vasculature features not } \\
\text { likely to be useful }\end{array}$ & $\begin{array}{l}\text { Shape, size and orientation of disc; } \\
\text { elevation of neuroretinal rim; } \\
\text { trunk position in nerve }\end{array}$ & 58.8 \\
\hline $\mathrm{E}$ & 86 & 5 & 2 & $\begin{array}{l}\text { CDR; location and branching of } \\
\text { vessels; titling and shape of } \\
\text { disc; color of optic nerve } \\
\text { (relative temporal pallor) }\end{array}$ & $\begin{array}{l}\text { Shape of disc; depth of cup; } \\
\text { branching pattern of vessels not } \\
\text { useful }\end{array}$ & 70.6 \\
\hline $\mathrm{F}$ & 84 & 5 & 3 & $\begin{array}{l}\text { Size and shape of disc; size of } \\
\text { cup; cilioretinal vessels may be } \\
\text { useful; arrangement and } \\
\text { direction of vessels may be } \\
\text { useful }\end{array}$ & $\begin{array}{l}\text { Size of disc; orientation of disc; } \\
\text { shape and depth of the cup; } \\
\text { orientation of the vessel trunk }\end{array}$ & 58.8 \\
\hline G & 84 & 4 & 4 & $\begin{array}{l}\text { Size of disc; size and shape of } \\
\text { cup; tilting of disc; } \\
\text { parapapillary atrophy; vascular } \\
\text { branching pattern likely not to } \\
\text { be useful }\end{array}$ & $\begin{array}{l}\text { Size and shape of disc; pattern of } \\
\text { vessels outside the disc margin; } \\
\text { nerve fiber layer volume not } \\
\text { useful }\end{array}$ & 64.7 \\
\hline $\mathrm{H}$ & 82 & 6 & 3 & $\begin{array}{l}\text { Size and shape of cup; size and } \\
\text { shape of disc; temporal vessel } \\
\text { branching pattern, parapapillary } \\
\text { pigmentation; depth of trunk } \\
\text { branching }\end{array}$ & $\begin{array}{l}\text { Shape and size of cup, shape and } \\
\text { size of disc; presence of } \\
\text { cilioretinal vessels; pattern of } \\
\text { vasculature }\end{array}$ & 70.6 \\
\hline I & 82 & 4 & 5 & $\begin{array}{l}\text { Vascular pattern; position of } \\
\text { vascular branching; size of disc; } \\
\text { site of maximum neuroretinal } \\
\text { rim thickness }\end{array}$ & $\begin{array}{l}\text { Size and orientation of the disc; } \\
\text { vascular pattern; parapapillary } \\
\text { abnormalities; contour of } \\
\text { neuroretinal rim }\end{array}$ & 52.9 \\
\hline $\mathrm{J}$ & 82 & 3 & 6 & $\begin{array}{l}\text { VCDR; parapapillary atrophy; site } \\
\text { of maximum neuroretinal rim } \\
\text { thickness (ISNT); size of disc; } \\
\text { displacement of vessels not } \\
\text { likely to be useful }\end{array}$ & $\begin{array}{l}\text { Arrangement or sectorial location of } \\
\text { cupping; vascular pattern }\end{array}$ & 64.7 \\
\hline K & 80 & 5 & 5 & $\begin{array}{l}\text { Size of disc; CDR; shape of disc } \\
\text { and cup }\end{array}$ & $\begin{array}{l}\text { Size of disc; CDR; shape of cup; } \\
\text { contour of neuroretinal rim }\end{array}$ & 64.7 \\
\hline $\mathrm{L}$ & 80 & 6 & 4 & $\begin{array}{l}\text { Size of disc; CDR; shape of disc; } \\
\text { degree of disc tilting; vascular } \\
\text { pattern }\end{array}$ & $\begin{array}{l}\text { Diameter of disc; choroidal pattern; } \\
\text { vascular pattern; shape of disc }\end{array}$ & 47.1 \\
\hline M & 78 & 8 & 3 & $\begin{array}{l}\text { Size and shape of disc; size of } \\
\text { cup; vasculature pattern; color } \\
\text { of parapapillary region; depth } \\
\text { of cup }\end{array}$ & $\begin{array}{l}\text { Size of disc; size of cup; pattern of } \\
\text { vessels; depth of cup; } \\
\text { parapapillary pigmentation }\end{array}$ & 82.4 \\
\hline $\mathrm{N}$ & 76 & 2 & 10 & $\begin{array}{l}\text { Size and shape of disc; shape of } \\
\text { cup; individual characteristics } \\
\text { likely to be less important than } \\
\text { overall gestalt of ONH pattern }\end{array}$ & $\begin{array}{l}\text { Pattern of choroid and retinal } \\
\text { pigment epithelium; blood vessel } \\
\text { pattern; neuroretinal rim width } \\
\text { not useful }\end{array}$ & 76.5 \\
\hline $\mathrm{O}$ & 74 & 7 & 6 & $\begin{array}{l}\text { Size of disc and cup; vessel } \\
\text { pattern; color of the optic } \\
\text { nerve }\end{array}$ & $\begin{array}{l}\text { Height of the optic nerve relative to } \\
\text { retinal plane; vessel pattern; optic } \\
\text { disc size more useful than cup } \\
\text { size; tilt of disc; parapapillary } \\
\text { atrophy }\end{array}$ & 64.7 \\
\hline
\end{tabular}

Data were collected in qualitative questioning before the experiment regarding the most heritable features of the optic nerve head and after the experiment about how the judgments were reached. CDR, cup-to-disc ratio; VCDR, vertical cup to disc ratio; ISNT, inferior $>$ superior $>$ nasal $>$ temporal neuroretinal rim sector thickness. 
FIGURE 3. Performance of ophthalmic experts and the relative usefulness of specific ONH features in determining zygosity. Left of the vertical line: graders, represented by $\mathrm{X}$; right: $\mathrm{ONH}$ items. More able graders and less useful items, for determining zygosity by $\mathrm{ONH}$ appearance are near the bottom. The $t$-standardized-information, weighted mean square statistic is displayed in parentheses, with the column of figures on the left representing the logit values of the rank-adjusted proportions. $\mathrm{s}, 1 \mathrm{SD}$; t, $2 \mathrm{SD}$; m, mean; OD, optic disc; OC, optic cup; CDR, cup-disc ratio; NRR, neuroretinal rim.

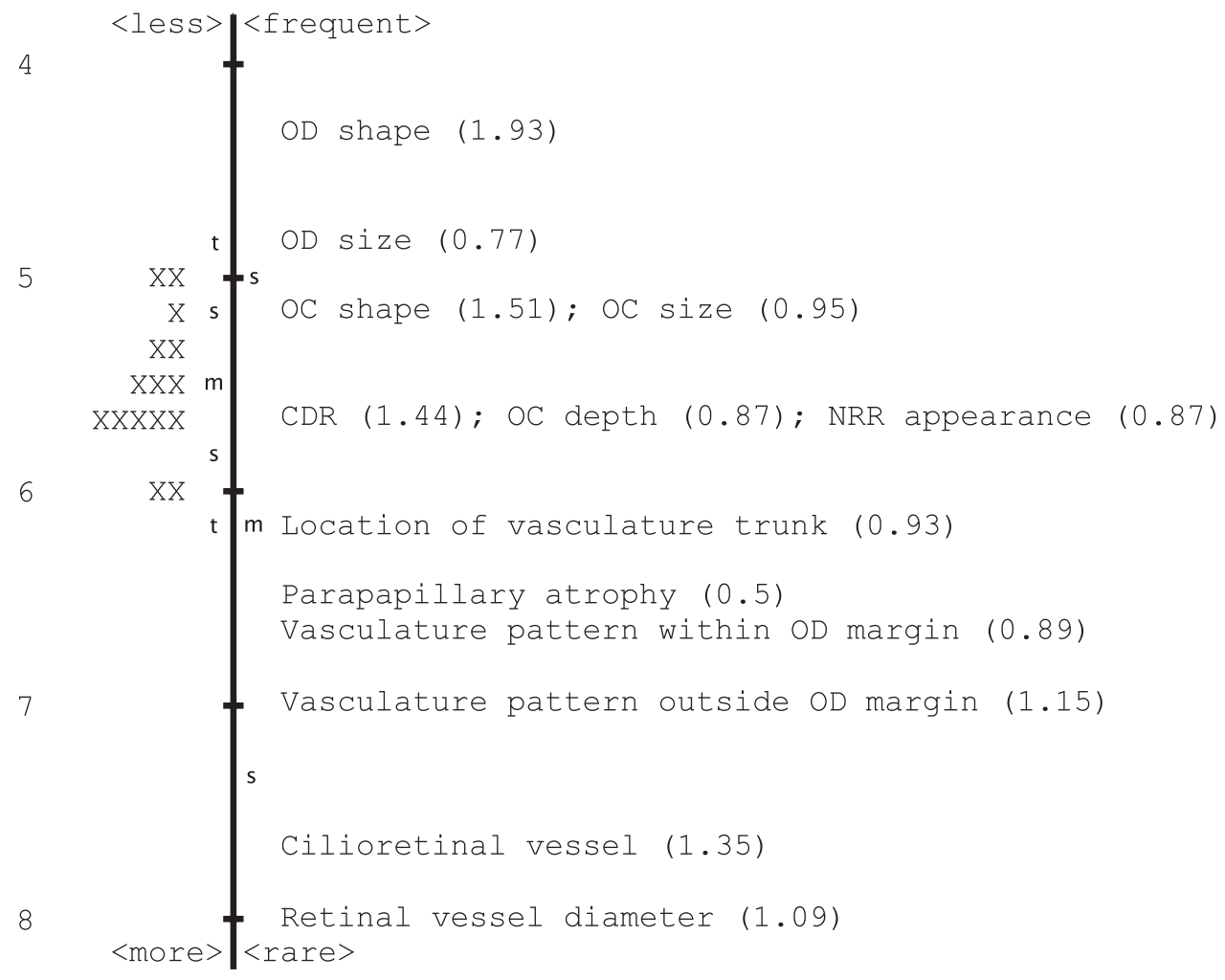

Two of the ophthalmic experts correctly determined zygosity in 45 of 50 twin pairs. The zygosity of 20 (40\%) twin pairs was correctly nominated by all 15 experts, whereas the zygosity of 3 (6\%) pairs (Fig. 2) was correctly identified by fewer than 5 of the graders.

For each expert and across the panel as a whole, the proportion of incorrect zygosity calls did not differ $(P>0.1)$ between the first and second halves of the viewed set. MZ twins were more frequently erroneously identified as DZ than vice versa (Table 1 ). The three graders who specified more DZ twins than MZ generally performed poorly on the grading, each with scores less than $84 \%$.

On completion of the experiment, each expert had an altered opinion regarding the traits that he or she believed were heritable, relative to the specific responses in the qualitative initial interview (Table 1). Rasch analysis of the quantitative weighting revealed that experts who correctly identified the zygosity in more than $85 \%$ of cases placed the most weighting on the size and shape of the optic disc and optic cup, whereas experts with the lowest scores placed greater weighting on the $\mathrm{ONH}$ vasculature (Fig. 3). The empirically adjusted ability of the experts, each represented by an $\mathrm{X}$ is displayed, with better-performing experts and less-useful ONH characteristics for determining zygosity appearing near the bottom of the graph. The item optic disc shape had noticeable off-variable noise (infit mean square, 1.93).

During the second experiment, the ONH photographs from the same individual were matched correctly in an average of $64.7 \%$ of the attempts (range, $47.1 \%-82.4 \%$ ). Across the experts, there was no correlation between the results of the zygosity-nominating experiment and the second ONH-matching experiment (Spearman's rho: $-0.16, P=0.27$ ). Two of the three best performing experts in this second experiment also had the greatest disparity in the proportion of twin zygosities incorrectly nominated as MZ or DZ (Table 1).

\section{Discussion}

The degree to which genes and environmental factors determine ONH morphology is of fundamental importance for the full understanding of the etiology of common blinding diseases such as glaucoma. We used a novel approach to dissect the heritable features of the $\mathrm{ONH}$. In determining the heritable components, the results of the study suggest that quantification of the shape and size of the optic disc and cup should receive a greater priority than quantification of $\mathrm{ONH}$ vascular features. Factors such as vascular pattern or tortuosity are difficult to quantify; hence, our findings are strengthened by the fact that this was a qualitative study rather than a quantitative one. The relative partitioning of genetic and environmental components of particular traits allows for informed investigation of underlying pathogenesis. Given the vast array of potentially quantifiable $\mathrm{ONH}$ structures, prioritizing those that should be investigated over others allows for efficient use of finite resources.

The tight coupling of $\mathrm{ONH}$ traits and disease underscores the relevance of the genetic liability that is associated with those specific features. ${ }^{4}$ Mutations in both nuclear and mitochondrial genes alter $\mathrm{ONH}$ architecture in the diseased state. $^{15-17}$ Glaucoma, a disease of progressive excavation of the optic disc, for example, has been demonstrated to have a genetic basis. ${ }^{18-20}$ It is noteworthy that each expert grader differed in their responses before and after completing the experiment. The initial unstructured questioning allowed exploration of the pre-experiment biases regarding heritable traits of the $\mathrm{ONH}$. Of note, in this initial questioning, optic disc size was regarded as the most important trait by 11 of the 15 experts. The postexperiment questioning gave insight into each grader's intuition on these heritable features. Three of the top five performing experts commented that vascular pattern was not useful in determining twin zygosity, whereas the four poorest performing graders principally used these features in determining the zygosity. 
In the second experiment, we investigated the relative phenomenon of mirroring, laterality and environment effects on the ONH. Unique environmental factors and variable expression of genetic factors (e.g., differences in methylation) may account for phenotypic differences in MZ twins. ${ }^{21}$ In classic twin studies, the equal-environment assumption is widely accepted, ${ }^{22}$ and within individuals there is a degree of ONH asymmetry. ${ }^{2}$ However, the $\mathrm{ONH}$ features of some MZ twins are surprisingly dissimilar, thereby suggesting that stochastic epigenetic events significantly influence $\mathrm{ONH}$ architecture. This phenomenon is the likely reason for the two sets of MZ twins pairs that most experts incorrectly determined as being DZ pairs in the initial experiment. Although the phenomenon of mirror imaging has been described in MZ twins, ${ }^{23,24}$ it does not appear to be of marked significance in $\mathrm{ONH}$ development. The principal limitation of this second experiment was the relatively small number of MZ twins used. Increasing both the number of expert graders and the number of twins used would allow for a clearer demarcation of traits commonly discordant between MZ twins and the possible identification of novel factors influencing the ONH appearance. ${ }^{25}$

Populations of twins provide a powerful opportunity for disentangling complex genetic and environmental interactions. ${ }^{22} \mathrm{~A}$ classic twin study allows analysis of the variance and covariance between $M Z$ and $D Z$ twin pairs. Comparison between the covariance of $\mathrm{MZ}$ and $\mathrm{DZ}$ twin pairs allows partitioning into dominant versus additive genetic components and shared versus nonshared environmental elements. ${ }^{22}$ A small number of low-powered twin studies have been conducted to investigate the $\mathrm{ONH}$, and these generally support the results of our findings. Twins were included in the cohort used by Armaly ${ }^{26}$ in his landmark paper in which he concluded that the CDR of the $\mathrm{ONH}$ was genetically determined. Subsequently, Schwartz et al. ${ }^{27,28}$ used ONH photographs from twins to estimate that the heritability of the CDR ranges between $70 \%$ and $80 \%$. Teikari and Airaksinen ${ }^{29}$ also identified greater CDR correlations between MZ twins than between DZ pairs. The parapapillary retinal nerve fiber layer thickness has been found to have a relatively high heritability (82\%), whereas the presence of cilioretinal arteries are influenced by additive genetic factors, with an estimated heritability of $71 \% .^{30,31}$ Huntzinger and Christian ${ }^{32}$ concluded that vascular tortuosity is likely to be more genetically determined than other features, such as vessel length, branching points, and number of vessels crossing the optic disc margin. Although family-based studies investigating ONH heritability have been focused on few phenotypic features, the findings also generally support the overall results of our study. The size of optic cup and disc ${ }^{33-35}$ have been found to be more hereditable than has retinal vessel thickness. ${ }^{36}$

In summary, Rasch analysis demonstrated that both the shape and size of the optic disc and cup were more useful in determining twin zygosity than were vascular parameters. Thus, these traits are particularly likely to be highly heritable. Nonetheless, epigenetic variation causes minor asymmetry of the ONH. Determining the genetic and environmental variants that influence ONH morphology will allow for the elucidation of the molecular pathogenesis of diseases that alter optic nerve architecture.

\section{Acknowledgments}

The authors thank John M. Linacre for assistance with the WinSteps programming.

\section{References}

1. Williams JT, Blangero J. Power of variance component linkage analysis-II. Discrete traits. Ann Hum Genet. 2004;68:620 - 632.

2. Jonas JB, Budde WM, Panda-Jonas S. Ophthalmoscopic evaluation of the optic nerve head. Surv Ophthalmol. 1999;43:293-320.
3. Fitzgibbon T, Taylor SF. Retinotopy of the human retinal nerve fibre layer and optic nerve head. J Comp Neurol. 1996;375:238-251.

4. Traboulsi E, ed. Genetic Diseases of the Eye. New York: Oxford University Press; 1998.

5. Airaksinen PJ, Drance SM, Douglas GR, Mawson DK, Nieminen H. Diffuse and localized nerve fiber loss in glaucoma. Am J Ophthalmol. 1984;98:566-571.

6. Yen MY, Wang AG, Wei YH. Leber's hereditary optic neuropathy: a multifactorial disease. Prog Retin Eye Res. 2006;25:381-396.

7. Zhu G, Evans DM, Duffy DL, et al. A genome scan for eye color in 502 twin families: most variation is due to a QTL on chromosome 15q. Twin Res. 2004;7:197-210.

8. Rinchik EM, Bultman SJ, Horsthemke B, et al. A gene for the mouse pink-eyed dilution locus and for human type II oculocutaneous albinism. Nature. 1993;361:72-76.

9. Duffy DL, Montgomery GW, Chen W, et al. A three-single-nucleotide polymorphism haplotype in intron 1 of OCA2 explains most human eye-color variation. Am J Hum Genet. 2007;80:241-252.

10. Nyholt DR. On the probability of dizygotic twins being concordant for two alleles at multiple polymorphic loci. Twin Res Hum Genet. 2006;9:194-197.

11. Linacre JM. WINSTEPS computer program for Rasch measurement. Chicago: winsteps.com; 2004.

12. Rasch $G$. An item analysis which takes individual differences into account. Br J Math Stat Psychol. 1966;19:49-57.

13. Pesudovs K, Garamendi E, Elliott DB. The Quality of Life Impact of Refractive Correction (QIRC) Questionnaire: development and validation. Optom Vis Sci. 2004;81:769-777.

14. Linacre JM. Rasch analysis of rank-ordered data. J Appl Meas. 2006;7:129-139.

15. Delettre C, Lenaers G, Griffoin JM, et al. Nuclear gene OPA1, encoding a mitochondrial dynamin-related protein, is mutated in dominant optic atrophy. Nat Genet. 2000;26:207-210.

16. Wallace DC, Singh G, Lott MT, et al. Mitochondrial DNA mutation associated with Leber's hereditary optic neuropathy. Science. 1988;242:1427-1430.

17. Alexander C, Votruba M, Pesch UE, et al. OPA1, encoding a dynaminrelated GTPase, is mutated in autosomal dominant optic atrophy linked to chromosome 3q28. Nat Genet. 2000;26:211-215.

18. Stoilov I, Akarsu AN, Sarfarazi M. Identification of three different truncating mutations in cytochrome P4501B1 (CYP1B1) as the principal cause of primary congenital glaucoma (Buphthalmos) in families linked to the GLC3A locus on chromosome $2 \mathrm{p} 21$. Hum Mol Genet. 1997;6:641-647.

19. Stone EM, Fingert JH, Alward WL, et al. Identification of a gene that causes primary open angle glaucoma. Science. 1997;275:668-670.

20. Rezaie T, Child A, Hitchings R, et al. Adult-onset primary openangle glaucoma caused by mutations in optineurin. Science. 2002; 295:1077-1079.

21. Singh SM, Murphy B, O'Reilly R. Epigenetic contributors to the discordance of monozygotic twins. Clin Genet. 2002;62:97-103.

22. Martin N, Boomsma D, Machin G. A twin-pronged attack on complex traits. Nat Genet. 1997;17:387-392.

23. Townsend GC, Brown T, Richards LC, et al. Metric analyses of the teeth and faces of South Australian twins. Acta Genet Med Gemellol (Roma). 1986;35:179-192.

24. Satoh K, Shibata Y, Tokushige H, Onizuka T. A mirror image of the first and second branchial arch syndrome associated with cleft lip and palate in monozygotic twins. Br J Plast Surg. 1995;48:601605.

25. Oates NA, van Vliet J, Duffy DL, et al. Increased DNA methylation at the AXIN1 gene in a monozygotic twin from a pair discordant for a caudal duplication anomaly. Am J Hum Genet. 2006;79:155162 .

26. Armaly MF. Genetic determination of cup/disc ratio of the optic nerve. Arch Opbthalmol. 1967;78:5-43.

27. Schwartz JT, Reuling FH, Feinleib M. Size of the physiologic cup of the optic nerve head: hereditary and environmental factors. Arch Opbthalmol. 1975;93:776-778.

28. Schwartz JT, Reuling FH, Feinleib M. Heritability study on size of the physiologic cup of the optic nerve head: a summary report. Acta Genet Med Gemellol (Roma). 1976;25:181-186. 
29. Teikari JM, Airaksinen JP. Twin study on cup/disc ratio of the optic nerve head. Br J Ophthalmol. 1992;76:218-220.

30. Hougaard JL, Kessel L, Sander B, Kyvik KO, Sorensen TI, Larsen M. Evaluation of heredity as a determinant of retinal nerve fiber layer thickness as measured by optical coherence tomography. Invest Ophthalmol Vis Sci. 2003;44:3011-3016.

31. Taarnhoj NC, Munch IC, Kyvik KO, et al. Heritability of cilioretinal arteries: a twin study. Invest Ophthalmol Vis Sci. 2005;46:38503854 .

32. Huntzinger RS, Christian JC. The retinal blood vessel patterns in twins. Prog Clin Biol Res. 1978;24:241-246.
33. Bengtsson $B$. The inheritance and development of cup and disc diameters. Acta Ophthalmol (Copenh). 1980;58:733-739.

34. Klein BE, Klein R, Lee KE. Heritability of risk factors for primary open-angle glaucoma: the Beaver Dam Eye Study. Invest Ophthalmol Vis Sci. 2004;45:59-62.

35. Chang TC, Congdon NG, Wojciechowski R, et al. Determinants and heritability of intraocular pressure and cup-to-disc ratio in a defined older population. Ophthalmology. 2005;112:1186-1191.

36. Xing C, Klein BE, Klein R, Jun G, Lee KE, Iyengar SK. Genome-wide linkage study of retinal vessel diameters in the Beaver Dam Eye Study. Hypertension. 2006;47:797-802. 